\title{
INNOVATING A CITY \\ THROUGH CITIZEN PARTICIPATION: COULD INTERDISCIPLINARY ORIENTATION PLAY A ROLE?
}

\author{
Adriana Zaiţ ${ }^{1}$ and Andreia Gabriela Andrei ${ }^{2}$
}

DOI: 10.24989/ocg.338.25

\begin{abstract}
This exploratory study is based on a grounded theory research performed with the intention to find new potential explanations for citizen participation to processes related to city innovation through public administration and e-governance initiatives.
\end{abstract}

Considering (1) the huge importance and amount of previous work on innovation, (2) the societal challenges with which we are confronted, most of them requiring multiple, system thinking type of knowledge and an interdisciplinary perspective, as well as (3) the need to transform our cities in better living and working places, one research question was raised: what does it take to make people more involved in the process of innovating a city, other than traditional factors previously investigated? It is a subject at the intersection of several fields and streams of research: public administration, innovative cities in terms of governance and e-government, civic participation and citizen science, researchers' skills and competencies, inter and transdisciplinary research - a complex array of intertwined challenges.

The research objective was to find out if interdisciplinary orientation could be considered among the influence factors that explain citizen participation. The grounded theory method was applied, based on the inductive approach, to generate future hypotheses. The research is exploratory and qualitative; we conducted a semi-structured group interview with 18 researchers, to identify the most important traits of human innovation, followed by a survey with 30 researchers to measure their perceptions towards interdisciplinary research. Researchers were used as an extreme case selection unit for the initial formulation of our research hypothesis, having in mind their double quality - highly educated people and citizens.

Our pilot study findings indicate that interdisciplinary orientation could be a significant explanatory factor for citizen participation, but further quantitative testing is necessary.

\section{Introduction}

Europe needs, asks and offers support for initiatives designed in favor of more innovative cities, human-centered, inclusive, safe, resilient and sustainable, in which citizens are involved and

\footnotetext{
${ }^{1}$ University Alexandru Ioan Cuza Iaşi, Department Management, Marketing and Business Administration, Bd. Carol I nr. 22, 700505 Iaşi, azait@uaic.ro

${ }^{2}$ University Alexandru Ioan Cuza Iaşi, Department Management, Marketing and Business Administration, Bd. Carol I nr. 22, 700505 Iaşi, andrei.andreia@gmail.com
} 
participate to the development of their local community, through co-creating approaches. [33], [34], [35], [36]. These desiderates change the whole picture in terms of governance, including egovernment, as well as in terms of skills and competencies required from various publics, from the narrowly specialized ones (academics, politicians, administrators etc.) to the large society as a whole (all citizens). Present global health challenges add supplementary concerns over citizen behavior and citizen's willingness and abilities to cope with radical behavioral changes. Civic engagement, in various forms - do something or quit doing something, in various ways $=$ offline and online, is desired and thoroughly analyzed, to better understand it and discover ways in which could be stimulated [1], [4], [12], [15], [24], [28], [33]. Be it policy people, local administrators, educators, researchers or citizens, they all need to go beyond their more or less narrow, specialized knowledge and interests, transgress disciplinary boundaries and adopt a more complex, inter and transdisciplinary perspective for solving societal problems at their level. Could interdisciplinary orientation have a role in explaining citizens' participation to the community life? Are we prepared for such an interdisciplinary approach?

The present research started with these rather philosophical questions, specific to grounded theory research designs, and got a more structured form during a course within a postgraduate program on innovation for doctoral and postdoctoral studies, which served as a small scale pilot exploratory research. Finding a research idea that brings together various research subjects and experiences from all fields of economics and business, allowing students to work on a common agenda is very similar to the way city's inhabitants need to act in order to solve common societal issues; we decided to use previous research backgrounds and results to suggest ways to make the city in which they all studied a more innovative one.

The whole approach is a grounded theory type of research design [20], in which exploratory, inductive reasoning is used (in contrast to a deductive approach based on previous theories and hypotheses testing). Grounded theory designs, developed by sociologists, begin with quite general questions and qualitative data collection, and try to develop the basis for new theories, other than the existing, traditional ones, giving the researcher freedom to generate new concepts with potential in explaining human behavior [20].

Considering the huge importance and amount of previous work on innovation, the societal challenges with which we are confronted, requiring an interdisciplinary perspective, as well as the need to transform our cities in better living and working places, the general research questions were further refined: what does it take to innovate a city, from the people's (human resource) perspective? How could a local public administration encourage citizen to adopt an innovative societal behavior? Do we have the openness towards various fields of study needed to understand the whole process and to get involved?

The subject is situated at the intersection of several fields and streams of research: inter and trans disciplinary research, public administration, innovative cities in terms of governance and egovernment, civic participation and citizen science, researchers' skills and competencies - a complex array of intertwined challenges. In line with grounded theory recommendations [20], we did not start with a literature review, but with an idea for a potential explanation of citizens' participation outside of the main streams of theories and researches; this idea was inductively generated by the observation of people's attitude towards civic engagement, during the course talk, and the ascertainment that participants having a mixed background (more than one previous degree specialization) were more prone to participate, at least at a stated level. From here, we moved to a next step - collecting data to see if it supports the nascent idea for a future theory testing. 
The exploratory research objective was twofold: to find out doctoral and postdoctoral students' (generally addressed throughout the paper as researchers) perceptions about the intangible human innovation required for innovating a city and to find out their orientation towards interdisciplinarity. We conducted a semi-structured group interview with 18 researchers, to identify their perceived important traits of human innovation, followed by a survey with 30 researchers to measure perceptions towards interdisciplinary research. Both samples were convenience type ones and partially overlapping: the 18 researchers used for the interview were those physically present to the first kick-off meeting of the innovative research postgraduate course module; 30 researchers (including the previously interviewed ones) represented the total number of participants enrolled in the course module on innovative research.

The rationale for this approach is rather simple: behind any aspect of public sector, e-democracy, ICT, e-government or e-citizen participation we have behavioral influence factors related to inner, innate traits (human nature), to environmental or development type variables (nurture), or a combination of these [31]. Education, disciplinary backgrounds and previous experiences with social norms contribute to a person's attitude and behavior; the more diverse are experiences, the higher is the likelihood for understanding various initiatives and the probability to get involved. In this light, interdisciplinary orientation could be a potential explanatory factor for citizen participation - a relationship that was not previously investigated.

\section{Literature review}

Our research started as a grounded theory approach, with some general questions, followed by a qualitative data collection through observation and informal interviews. Only after these initial steps we moved to the third stage, the literature review; a survey of the theory was performed, to test the viability of the potential explanation revealed during the first two stages from a theoretical point of view.

Several rounds of literature search were performed, first using key words pertaining to the specific fields of research (e-government, public administration, citizen participation, city innovation). In a second phase, an intersection of fields was performed and results analyzed, using all possible combinations of the four groups of key words related to the main fields of research. The final result was a search with common words, and thus a number of studies from eGovernance, eParticipation etc. which had in common the idea of interdisciplinarity. We shortly present, as it follows, the main identified themes.

In recent years, the volume and pace of research on topics like e-government, e-public administration, innovative cities, or citizen involvement has increased considerably [4], [9], [10], [22], [26], [25]. A diversity of referent domains and ideas can be noticed, with more and more investigators emphasizing the need to strengthen research and practical implications considering multiple theories, methods and fields - from law, sociology, politics, economics, management, marketing, philosophy, communication, information science, computer science, ethics [5], [10], [16], [17], [18]. If the desire to develop 'human-centered' or citizen centered services, especially e-government ones, to provide timely, accessible, relevant information and quality services should be transformed into action and applied in practice, then traditional 'brick and mortar' approaches, narrowly specialized are not enough, and various government agencies need to find out more types of factors with possible influence on citizen adoption of innovative services [4]. We retained, thus, the main categories or codes for this section of the literature review - influence factors for citizen behavior, and multiple approaches. 
Public administration is a complex applied social science, still struggling to better define its place; despite the internal controversies in terms of paradigms, research traditions, epistemologies, and modes of thought, or despite the fact that it is generally divided either along an academic dimension versus a vocational one, or an educational focus versus a research one [22], scholars agree that their knowledge and thinking should raise above singular disciplinary perspectives, for being able to suggest solid, sustainable solutions to the more and more complex societal challenges. Interdisciplinary cooperation and integration is needed, and so are real exchanges between scholars, often leading to transdisciplinarity and new insights. [5], [22]. Again, we find various influence factors, and interdisciplinary approach, as main codes for this second group of articles.

The exponential development of ICTs or Social networks impacted almost every facet of our lives and societies, including or especially concerning city governance and public administration; researchers try to respond to these challenges through massive interdisciplinary research [14], [15], [27]. Although some scholars speak about a painful dilemma in public administration - independence or interdisciplinarity [21], governance is considered itself a deeply interdisciplinary concept [32].

Without citizens' involvement and usage, any project would be meaningless; citizen engagement is a core concept of participatory planning and e-governance. Citizens need knowledge, knowledge is created and distributed, and these mechanisms require, again, interdisciplinary approaches [19]. Research on finding explanations for citizens' participative behavior increased, as well [1], [4], [12],[14], [15], [21], [28], [29]. So, for this third stream of literature, same codes - influence factors and interdisciplinarity.

We searched further for the interdisciplinarity concept in itself - fourth stream of literature. Although skepticism towards interdisciplinarity existed and still exists, interdisciplinary research seems to be a global agenda to scholars, due to increased interconnection between disciplines [2], [3], [5], [8], [11]. Everywhere someone calls for interdisciplinarity - in science, in higher education policy, in sociology, in politics, etc., as a concern towards a too narrow, overspecialized science, distanced from society and its needs [23] The way interdisciplinarity develops is interesting: either through a re-combination of disciplines or specialties from within science (especially through transfers and adoption of methods), or through across boundaries cooperation due to external impulses from research and political bodies. The first approach leads - paradoxically - to increased specialization and new disciplines formed from the previously combined ones; these new disciplines need to define their new, specific identity, and end up using a similar methodological nationalism and new disciplinary fences that were used by the disciplines from which they have been split. The second approach leads, in the end and if properly managed, to transdisciplinary research, with applied societal implications. The evolution of disciplinary and interdisciplinary fields is somehow similar to processes from biology, later applied to sociology [7]: cladogenesis and anagenesis. When a parent species splits into to distinct ones, with common ancestors, biologists speak about clades - and some scientific monodisciplines were formed like this. In contrast, anagenesis supposes a gradual evolution of a species that continues to exist as an interbreeding population - it would be the case for interdisciplinary researches. In social sciences this process of anagenesis or aromorphosis leads to widely diffused social innovation, raising adaptability and interconnectedness - same thing that would or should happen in interdisciplinary and transdisciplinary research.

As a conclusion of the literature search, the new potential explanatory theory of a relationship between interdisciplinary orientation and citizen participation makes sense, is highly plausible. In all these processes (e-government, e-democracy, city innovation etc.) specific skills are needed interdisciplinary ones - for a meaningful participation of all actors, not only citizens, although the 
way citizens learn these skills is still controversial [1]. Citizens need skills for learning to be participative and effective, to communicate, to connect in networks and groups, to take action - online and offline, as well, to exercise civic rights and contribute to the innovative change of their cities [1], [14], [15], [28]. Researchers are citizens as well, but they have an even more important role, to discover not only what motivates themselves, but also what motivates others in such an enterprise. This is why we wanted to find out what researchers feel about interdisciplinarity, and moved to the next stage of our exploratory research: measure interdisciplinary attitudes.

\section{Methodology and main findings}

The research was an exploratory one, with the intent to identify and describe the most important variables that could be used in a future causal study in the field of relationships between interdisciplinary research orientations and other institutional and individual variables, if public administration and e-governance initiatives should be embraced, respected and supported by citizens. Researchers were used as a pilot sample, based on the idea of the extreme case selection [6]: they are the category with the largest amount of information on various fields, the most educated public, from which we would have the highest expectations in terms of civic involvement and interdisciplinary collaboration.

We first employed a semi-structured laddering type group interview with 18 researchers, in order to find out what researchers think about people's reactions in a community, whenever some type of change - for example an innovative behavior towards a city - is expected and intended by local public administration/government people. The starting question was: "What are, in your opinion, the most important concepts/factors influencing people's attitude towards a change in societal behavior?" Each respondent expressed an opinion, the answers being transcribed and then analyzed, using the content analysis as method, based on the emerging coding procedure. Three categories of factors were obtained: way of reasoning/thinking, personal beliefs/convictions and mentality/culture. For each of the three categories the interview continued with the next ladder step question: "What do you understand by way of reasoning?", "What are personal beliefs/convictions?", "What do you understand by mentality/culture?" Again, all answers were registered and a second round of content analysis was performed, to extract more specific influence factors. The main common variables identified during this stage were: information processing, individual values, social norms, and habits. With these potential influence factors we moved to a quantitative research, still exploratory in nature, in order to find out researchers' information, individual orientations and values, as well as habits in terms of doing research in general and towards interdisciplinarity in particular.

The questionnaire was taken from a study designed for a previous research, with several separate objectives [30], and had 42 questions, from which 33 related to latent variables of interest (interdisciplinary orientation, intellectual capital, profile of research collaborations etc.) and the rest being descriptive questions for the respondents' academic profile. We selected from the total response data file only those questions pertaining to the present research, and the results (descriptive statistics - frequencies) are presented in Table 1. 


\begin{tabular}{|c|c|c|c|c|c|c|c|}
\hline Questions & SD & D & $\mathbf{N}$ & $\mathbf{A}$ & $\mathbf{S A}$ & $\begin{array}{l}\text { SD+ } \\
\text { D }\end{array}$ & $\begin{array}{c}\text { SA+ } \\
\mathbf{A}\end{array}$ \\
\hline $\begin{array}{l}\text { 1. I value reading about topics outside of my } \\
\text { primary field }\end{array}$ & 0 & 3.3 & 16.7 & 46.7 & 33.3 & 3.3 & 80 \\
\hline $\begin{array}{l}\text { 2. I enjoy thinking about how different fields } \\
\text { approach the same problem in different ways }\end{array}$ & 0 & 3.3 & 6.7 & 36.7 & 53.3 & 3.3 & 90 \\
\hline $\begin{array}{l}\text { 3. Not all problems in my field of research are } \\
\text { relevant only for my own field of research }\end{array}$ & 0 & 0 & 13.3 & 43.3 & 43.3 & 0 & 86.6 \\
\hline $\begin{array}{l}\text { 4. Not all problems in my field of research } \\
\text { can be solved by people from my own field }\end{array}$ & 0 & 3.3 & 20 & 30 & 46.7 & 3.3 & 76.7 \\
\hline $\begin{array}{l}\text { 5. In solving research problems in my primary } \\
\text { field of research I often seek information } \\
\text { from experts in other academic fields }\end{array}$ & 0 & 16.7 & 16.7 & 33.3 & 33.3 & 16.7 & 66.6 \\
\hline $\begin{array}{l}\text { 6. When I'm given knowledge and ideas from } \\
\text { different fields than mine, I can figure out the } \\
\text { appropriate way for solving a problem in } \\
\text { those fields }\end{array}$ & 3.3 & 6.7 & 26.7 & 50 & 13.3 & 10 & 63.3 \\
\hline $\begin{array}{l}\text { 7. I see connections between ideas in my field } \\
\text { and ideas in quite different fields (for } \\
\text { example, from technical or science to } \\
\text { humanities and arts) }\end{array}$ & 0 & 6.7 & 23.3 & 40 & 30 & 6.7 & 70 \\
\hline $\begin{array}{l}\text { 8. I can take ideas from outside my field and } \\
\text { synthesize them in a way easy to be } \\
\text { understood by others }\end{array}$ & 0 & 6.7 & 16.7 & 46.7 & 30 & 6.7 & 76.7 \\
\hline $\begin{array}{l}\text { 9. I often step back and reflect on what I'm } \\
\text { thinking, to determine whether I might be } \\
\text { missing something }\end{array}$ & 0 & 0 & 26.7 & 26.7 & 43.3 & 0 & 70 \\
\hline $\begin{array}{l}\text { 10. I frequently stop to think about where I } \\
\text { might be going wrong or right with a problem } \\
\text { solution }\end{array}$ & 0 & 13.3 & 10 & 36.7 & 40 & 13.3 & 76.7 \\
\hline $\begin{array}{l}\text { 11. I recognize the kinds of evidence that } \\
\text { different sciences or fields of study rely on }\end{array}$ & 0 & 16.7 & 23.3 & 46.7 & 13.3 & 16.7 & 60 \\
\hline $\begin{array}{l}\text { 12. I'm good at figuring out what experts in } \\
\text { different fields have missed in explaining a } \\
\text { problem or a solution }\end{array}$ & 3.3 & 33.3 & 40 & 20 & 3.3 & 36.6 & 23.3 \\
\hline $\begin{array}{l}\text { 13. I tend to be more productive working on } \\
\text { research problems with people from my field } \\
\text { than working in a research team with } \\
\text { members from various fields }\end{array}$ & 3.3 & 20 & 13.3 & 43.3 & 20 & 23.3 & 63.3 \\
\hline $\begin{array}{l}\text { 14. It is important to focus my research } \\
\text { efforts with others in my own field/discipline }\end{array}$ & 0 & 6.7 & 20 & 43.3 & 30 & 6.7 & 73.3 \\
\hline $\begin{array}{l}\text { 15. The benefits of collaboration among } \\
\text { scientists from different fields usually } \\
\text { outweigh the costs and publication } \\
\text { inconveniences of such collaborative work }\end{array}$ & 0 & 13.3 & 23.3 & 50 & 13.3 & 13.3 & 63.3 \\
\hline
\end{tabular}


The first four questions (1-4) refer to the researchers' general attitude towards interdisciplinary collaboration. The next four (5-8) describe their behavior in terms of interdisciplinarity. Questions 9 to 12 relate to researchers reflective capacity (which is an antecedent of interdisciplinary orientation) and their confidence in their own interdisciplinary skills. The last three questions (13-15) describe researchers' perceived usefulness of getting involved in interdisciplinary research.

\section{Discussions and conclusions}

Researchers have a good attitude about interdisciplinary collaboration, with higher percentages (ASA) appreciating the theoretical and passive side (reading, observing) rather than the active one (being involved in doing it, in solving problems). We can notice the percentages of disagreement for questions 3 and 4, suggesting a higher trust in solving problems inside their disciplinary field, which is in line with what we find in the real world. The proportion of people not valuing totally the idea of interdisciplinarity worth being noticed, as well - again, in line with what happens in real life, where fields are rather separated, insular and tribal [2].

When looking at stated behavior, we can notice that although a comfortable majority (more than 60\%) of researchers crosses their discipline's boundary for getting information, a rather worrying percentage doesn't - and if this highly educated and informed segment of population doesn't, we cannot expect regular citizens to do more. Reflective capacity and confidence in seeing connections between fields or communicating across fields are also comfortably high, yet at the same time worrying if we consider researchers as being able to have the largest interconnected perspective about societal issues to be solved.

Finally, the answers to the last three questions show that mono-disciplinary work is considered more productive, more important and more beneficial in terms of costs and benefits (especially publication). It is not a surprising result, since previous studies on interdisciplinary work suggested similar positions and worries for researchers ([2], [3], [18]), and since interdisciplinary work is more difficult to evaluate and publications in interdisciplinary journals are quite often less valued for promotions.

Although several limitations exist for this exploratory study (limited samples, convenience selection procedure, researchers belonging to the same field - economics and business studies, risks of subjective interpretations for content analyses due to the fact that both authors come from the same field), it could be a good starting point for a future quantitative study and especially for reconsidering the way we prepare researchers first, and then policy people and citizens, as a whole, for interdisciplinary knowledge, collaborative work and participatory civic activities.

Innovating our cities will require a higher effort for an interdisciplinary orientation, comprehension and behavior. Getting people or citizens more participative and engaged, either offline or online, improving e-participation and governance could be obtained by a shift in education, towards a greater interdisciplinarity curricula. This is the hypothesis generated by our exploratory research based on grounded theory principles - hypothesis that needs further testing and investigation.

\section{References}

[1] ASHTARIA, D. and DE LANGEB, M., Playful civic skills: A transdisciplinary approach to analyze participatory civic games, Cities 89 (2019) 70-79. 
[2] BECHER, T. and TROWLER. P.R., Academic Tribes and Territories Intellectual enquiry and the culture of disciplines, Open University Press, 2001, Celtic Court 22, Ballmoor, Buckingham.

[3] BORREGO, M. and NEWSWANDER, L. K., Definitions of Interdisciplinary Research: Toward Graduate-Level Interdisciplinary Learning Outcomes, The Review of Higher Education 34(1), 2010, 61-84. doi:10.1353/rhe.2010.0006

[4] CARTER, L., BELANGER, F., The utilization of e-government services: citizen trust, innovation and acceptance factors, Information Systems Journal, Vol 15, Iss 1, Pages: 5-25, Jan 2005, DOI: 10.1111/j.1365-2575.2005.00183.x.

[5] CHANTHAMITH, B., WU, M., YUSUFZADA, S. and RASEL, M., Interdisciplinary relationship between sociology, politics and public administration: Perspective of theory and practice, Sociology International Journal 2019;3(4):353-357.

[6] FLYVBJERG, B., Five Misunderstandings About Case-Study Researc, Qualitative Inquiry, vol. 12, no. 2, April 2006, pp. 219-245. DOI: 10.1177/1077800405284363.

[7] GRININ, L. and KOROTAYEV, A., Social Macroevolution: Growth of the World System Integrity and a System of Phase Transitions. World Futures. 2009, 65 (7): $477-$ 506. doi:10.1080/02604020902733348.

[8] GUERREIRO, J. A., Interdisciplinary Research In Social Sciences: A Two Way Process?, Proceedings of the International Congress on Interdisciplinarity in Social and Human Sciences, 5th - 6th May 2016, University of Algarve, Faro, Portugal.

[9] HARDY, C. A. and WILliAMS, S. P., Assembling E-Government Research Designs: A Transdisciplinary View and Interactive Approach, Public Administration Review, Vol 71, Iss 3, Pages: 405-413, 2011, DOI: 10.1111/j.1540-6210.2011.02361.x.

[10] HEEKS, R. and BAILUR, S., Analyzing e-government research: Perspective, philosophies, theories, methods, and practice, Government Information Quarterly, Vol 24, Iss 2, Pages: $243-$ 265, 2007, DOI: 10.1016/j.giq.2006.06.005.

[11] KAHAN, D. M., JENKINS-SMITH, H. and BRAMAN, D., Cultural cognition of scientific consensus, Journal of Risk Research, 2011, 14:2, 147-174, DOI:10.1080/13669877.2010.5112 46.

[12] LE COMPTE, K., BLEVINS, B. and RIGGERS-PIEHL, T., Developing civic competence through action civics: A longitudinal look at the data, The Journal of Social Studies Research, Vol 44, 2020, pp.127-137.

[13] LEDFORD, H., How to solve the world's biggest problems, Nature | News Feature, 16 September 2015.

[14] MISURACA, G. and PASI, G., Landscaping digital social innovation in the EU: Structuring the evidence and nurturing the science and policy debate towards a renewed agenda for social change, Government Information Quarterly, 36, 2019, pg. 592-600. 
[15] MOSES, J. F., DWYER, P. C., FUGLESTAD, P., KIM, J., MAKI, A., SNYDER, M. and TERVEEN, L., Encouraging online engagement: The role of interdependent self-construal and social motives in fostering online participation, Personality and Individual Differences 133, 2018, pg. 47-55.

[16] MÜLLER, E., Introduction: Interdisciplinary Concepts and their Political Significance, Contributions to the History of Concepts, Volume 6, Issue 2, Winter 2011: 42-52, doi:10.3167/choc.2011.060203.

[17] PILEMALM, S., LINDGREN, I. and RAMSELL, E., Emerging forms of inter-organizational and cross-sector collaborations in e-government initiatives. Implications for participative development of information systems, Transforming Government- People Process and Policy, Vol 10, Iss 4, Pages: 605-636, 2016, DOI: $\quad$ 10.1108/ TG-12-2015-0055.

[18] SCHOLL, H. J., Central research questions in e-government, or which trajectory should the study domain take?, Transforming Government People Process and Policy, Vol 1, pg 67-88 2007,DOI:10.1108/17506160710733715.

[19] SHI, S., ZHANG, WY., ZHANG, S. and CHEN, J., Does prestige dimension influence the interdisciplinary performance of scientific entities in knowledge flow? Evidence from the egovernment field, Scientometrics, Vol 117, Iss 2, Pages: 1237-1264, 2018, DOI: 10.1007/s11192-018-2914-4.

[20] STRAUSS, A. and CORBIN, J., Grounded Theory Methodology: An Overview, in N. DENZIN \& Y. LINCOLN, Handbook of Qualitative Research. 1st ed., 1994, pg. 273-284.

[21] VIGODA, E., Rethinking The Identity Of Public Administration: Interdisciplinary Reflections And Thoughts On Managerial Reconstruction, Public Administration \& Management: An Interactive Journal, 8, 1, 2003, pp. 1- 22.

[22] VAN DER WALDT, G., Public Administration and Transdisciplinarity: A Modalistic Approach toward Knowledge Co-Construction, International Journal of Humanities and Social Science Vol. 4, No. 6; April 2014, 120.

[23] WEINGART, P. A., A Short History of Knowledge Formations. In R. Frodemann, J. Thomson Klein, \& C. Mitcham (Eds), The Oxford Handbook of Interdisciplinarity. Oxford: Oxford University Press, 2010, 3 - 14.

[24] WHITMARSHA, L. and CORNERB, A., Tools for a new climate conversation: A mixedmethods study of language for public engagement across the political spectrum, Global Environmental Change, 42, 2017, pg. 122-135.

[25] WHITTY, M. T., DOODSON, J., CREESE, S. and HODGES, D., A picture tells a thousand words: What Facebook and Twitter images convey about our personality, Personality and Individual Differences, 133, 2018, pg. 109-114.

[26] WIRTZ, BW., DAISER, P. and BINKOWSKA, B., E-participation: A Strategic Framework, International Journal Of Public Administration, Vol 41, Iss 1, Pages: 1-12, 2018, DOI: 10.1080/01900692.2016.1242620. 
[27] YANG, Y., Towards a New Digital Era: Observing Local E-Government Services Adoption in a Chinese Municipality, Future Internet 2017, 9, 53; doi:10.3390/fi9030053.

[28] ZAIT, A. and ANDREI, A. G., Civic Engagement at the Crossroads of Online and Offline Spaces: A PLS-SEM Assessment, Scientific Annals of Economics and Business 66 (4), 2019, 559-572 DOI: 10.2478/saeb-2019-0045.

[29] ZAIT, A., Exploring the role of civilizational competences for smart cities' development, Transforming Government People Process and Policy, 11(2):00-00, 2017, DOI:10.1108/TG07-2016-0044.

[30] ZAIT, A., ANDREI, A. G. and HORODNIC, I. A., Interdisciplinary research - an instrument for measuring knowledge, skills and attitudes, 7th BSLab Symposium, Alicante, 2020. (extended abstract).

[31] ZAKY, E. A., Nature, Nurture, and Human Behavior; an Endless Debate, Journal of Child \& Adolescent Behavior, 2015, 3-6, doi: 10.4172/2375-4494.1000e107.

[32] ZUMBANSEN, P., The Conundrum of Order: The Concept of Governance from an Interdisciplinary Perspective, Comparative Research in Law \& Political Economy Research Papers, Working Papers, Conference Papers, Research Report No. 37/2010.

[33] nA, SET - the toolkit to engage citizens in co-creating their cities, EIP-SCC NEWS, 04.12.2018, Marketplace Editorial, https://eu-smartcities.eu/index.php/news/.

[34] nA, Innovating Cities, Making cities inclusive, safe, resilient and sustainable through innovative, coordinated and systemic solutions for the urban environment, https://ec.europa.eu/ research/environment/index.cfm?pg=home.

[35] nA, The human-centred city: Opportunities for citizens through research and innovation, Report of the High-Level Expert Group on Innovating Cities, Directorate-General for Research and Innovation, 2019.

[36] nA, Social innovation in cities, Urbact II capitalisation, April 2015. 